\title{
Positive Chronotropic and Negative Inotropic Effects Induced by Potassium Chloride in the Isolated Canine Atrium
}

\author{
Shigetoshi Chiba \\ Department of Pharmacology, Faculty of Medicine. Shinshu \\ University, Matsumoto
}

\begin{abstract}
ChrBa, S. Positive Chronotropic and Negative Inotropic Effects Induced by Potassium Chloride in the Isolated Canine Atrium. Tohoku J. exp. Med., 1976, 119 (1), 101-102 — The effects of potassium chloride on inotropic and chronotropic activity were investigated in five isolated canine atrium preparations which were suspended in a bath and perfused with arterial blood from the carotid artery of the heparinized support dog. Potassium chloride administered into the cannulated sinus node artery in a dose range of $100 \mu \mathrm{g}-1 \mathrm{mg}$ produced a doserelated negative inotropic and a positive chronotropic effect. These effects were not influenced by treatment with either atropine or propranolol. From these results, it is concluded that potassium has a direct negative effect on atrial contractility and a direct positive effect on atrial rate. —— isolated dog atrium; sinus node artery
\end{abstract}

In 1970, Hashimoto et al. demonstrated that the sinus rate was increased by raising the potassium concentration in the in situ SA node preparation of the dog. However, they did not measure the contraction. Recently, Chiba et al. (1975) developed the isolated, blood-perfused atrium preparation for the simultaneous measurements of the atrial rate and atrial contractile force. Thus, in the present study, an attempt was made to investigate chronotropic and inotropic responses to potassium chloride in the isolated atrium.

Five isolated atrium preparations were perfused with heparinized arterial blood led from a support dog anesthetized with $30 \mathrm{mg} / \mathrm{kg}$ of sodium pentobarbital. The details of the preparations were described in a previous paper (Chiba et al. 1975).

When potassium chloride was injected into the sinus node artery, a positive chronotropic and negative inotropic response was usually observed in a dose range of 100 $\mu \mathrm{g}$ to $1 \mathrm{mg}$ in all five preparations. No tachyphylaxis could be observed. Fig. 1 shows a typical response to $1 \mathrm{mg}$ of potassium chloride on an isolated atrium. At a larger dose level above $3 \mathrm{mg}$ of potassium chloride, the sinus acceleration and a profound depression of contraction were suddenly interrupted by cessation of atrial depolarization. Potassium chloride-induced negative inotropic response was not suppressed by the treatment with atropine in 2 experiments. Potassium chloride-induced positive chronotropic effect was not modified by propranolol treatment in 2 experiments. Thus, these effects were not mediated through the autonomic nervous mechanism.

Previously, Hashimoto et al. (1970) reported in the in situ canine SA node preparation that a high potassium solution caused sinus acceleration and that the simus rhythm abruptly disappeared at plasma concentrations higher than 8-10 $\mathrm{mE} / \mathrm{liter}$. The present study in the isolated atrium exactly confirmed their results. Concerning inotropism, there have been many studies on isolated heart preparations in order to investigate the

Received for publication, March 6, 1976. 


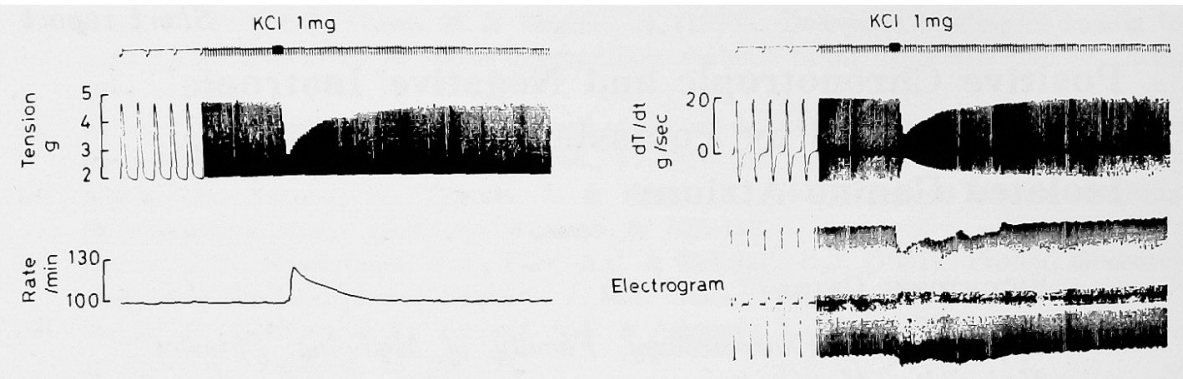

Fig. 1. Negative inotropic and positive chronotropic effects of $1 \mathrm{mg}$ of potassium chloride on a spontaneously beating atrium preparation of the dog. Time scale shows 1-sec intervals.

effect of increases in potassium concentration. They reported that increases in extracellular potassium concentration to levels still compatible with propagated excitation caused variable changes in the contractile force of mammalian cardial muscle; i.e., a negative inotropic effect (Engstfeld et al. 1961; Sarnoff et al. 1966; Kavaler et al. 1972), no inotropic effect (Goodyer et al. 1964), or a positive inotropic effect (Kavaler et al. 1972). In this study, potassium chloride induced only a negative inotropic effect in all trials. It was suggested that the negative inotropic effect of potassium can be attributed mainly to a potassium-induced reduction in the amplitude and/or duration of the action potential plateau (Kavaler et al. 1972).

Further studies are needed to compare potassium effects on atrial and ventricular muscles of the dog heart, because it has been reported that responses of atrial and ventricular muscles to the drug are frequently different as reported previously (Chiba et al. 1975; Chiba and Himori 1975).

\section{References}

1) Chiba, S. \& Himori, N. (1975) Different inotropic responses to adenosine on the atrial and ventricular muscle of the dog heart. Jap. J. Pharmacol., 25, 489-491.

2) Chiba, S., Kimura, T. \& Hashimoto, K. (1975) Muscarinic suppression of the nicotinic action of acetylcholine on the isolated, blood-perfused atrium of the dog. Naunyn-Schmiedeberg's Arch. Pharmacol., 289, 315-325.

3) Engstfeld, G., Antoni, H. \& Fleckenstein, S. (1961) Die Restitution der Erregungsfortleitung und Kontraktionskraft des $\mathrm{K}^{+}$-gelähmten Frosch- und Säugetiermyokards durch Adrenalin. Pfuegers Arch. Europ. J. Physiol., 273, 145-163.

4) Goodyer, A.V., Goodkind, M.J. \& Stanley, E.J. (1964) The effects of abnormal concentrations of the serum electrolytes on left ventricular function in the intact animal. Amer. Heart $J ., 67,779-791$.

5) Hashimoto, K., Suzuki, Y. \& Chiba, S. (1970) Effect of potassium excess on pacemaker activity of canine sinoatrial node in vivo. Amer. J. Physiol., 218, 83-87.

6) Kavaler, F., Hyman, P.M. \& Lefkowitz, R.B. (1972) Positive and negative inotropic effects of elevated extracellular potassium level on mammalian ventricular muscle. J. gen. Physiol., 60, 351-365.

7) Sarnoff, S.J., Gilmore, J.P., McConald, R.H., Daggett, W.M., Weisfedlt, M.L. \& Mansfield, P.B. (1966) Relationship between myocardial $\mathrm{K}^{+}$balance, $\mathrm{O}_{2}$ consumption, and contractility. Amer. J. Physiol., 211, 361-375. 